\title{
Analysis of the rs2476601 polymorphism of PTPN22 in Mexican mestizo patients with leprosy
}

\author{
MÓNICA ESCAMILLA-TILCH ${ }^{1}$, THALÍA GABRIELA PÉREZ-SUÁREZ ${ }^{1}$, \\ NORA MAGDALENA TORRES-CARRILLO ${ }^{2}$, ROSARIO RODRÍGUEZ-GUILLÉN ${ }^{3}$, \\ ROBERTO ARENAS-GUZMÁN ${ }^{4}$, MARCELA TORRES-HERNÁNDEZ ${ }^{5}$, \\ MARY FAFUTIS-MORRIS ${ }^{6}$, SERGIO ESTRADA-PARRA ${ }^{7}$, IRIS ESTRADA-GARCÍA ${ }^{7}$, \\ MARICELA GARCÍA-LECHUGA $^{8}$, JULIO GRANADOS $^{8}$ and ROSALIO RAMOS-PAYAN ${ }^{9}$
}

\begin{abstract}
${ }^{1}$ Coordinación de Investigación, Centro Médico Nacional '20 de Noviembre', Instituto de Seguridad y Servicios Sociales de los Trabajadores del Estado, Mexico City 03100; ${ }^{2}$ Departamento de Microbiología y Patología, Centro Universitario de Ciencias de la Salud, Universidad de Guadalajara, Guadalajara, Jalisco 44340; ${ }^{3}$ Unidad de Biología Molecular y

Medicina Genómica, Instituto Nacional de Ciencias Médicas y Nutrición Salvador Zubirán, Mexico City 14000; ${ }^{4}$ Sección de Micología, Hospital General Dr. Manuel Gea González, México City 14080; ${ }^{5}$ Hospital Regional de Psiquiatría, Héctor H. Tovar Acosta, Instituto Mexicano del Seguro Social, Mexico City 14070; ${ }^{6}$ Centro de Investigación en Inmunología y Dermatología, Instituto Dermatológico de Jalisco, Departamento de Fisiología, Centro Universitario de Ciencias de la Salud, Universidad de Guadalajara, Guadalajara, Jalisco 44340; ${ }^{7}$ Departamento de Inmunología, Escuela Nacional de Ciencias Biológicas, Instituto Politécnico Nacional, Mexico City 11340; ${ }^{8}$ Departamento de Trasplantes, División de Inmunogenética, Instituto Nacional de Ciencias Médicas y Nutrición Salvador Zubirán, Mexico City 14000; ${ }^{9}$ Laboratory of Immunology, Faculty of Biological and Chemical Sciences, Autonomous University of Sinaloa, Culiacán, Sinaloa 80010, México
\end{abstract}

Received February 8, 2018; Accepted December 18, 2018

DOI: $10.3892 /$ br.2019.1184

\begin{abstract}
Leprosy, a human chronic granulomatous disease caused by Mycobacterium leprae (M. leprae), remains endemic in certain countries despite the use of multidrug therapy. Recently, several host genes modulating the immune responses to $M$. leprae infection have been suggested to influence the acquisition and clinical course of leprosy. Lymphoid protein tyrosine phosphatase, encoded by the protein tyrosine phosphatase non-receptor type 22 (PTPN22) gene, serves a negative regulatory role in $\mathrm{T}$ cell activation. The non-synonymous single-nucleotide polymorphism (SNP) rs2476601 (1858C $>$ T) has been associated with autoimmune diseases. Here, the present study investigated if rs2476601 polymorphism was associated with leprosy in a Mexican mestizo population. Genotyping was performed in patients with leprosy $(\mathrm{n}=189)$ and control subjects $(\mathrm{n}=231)$
\end{abstract}

Correspondence to: Dr Rosalio Ramos-Payan, Laboratory of Immunology, Faculty of Biological and Chemical Sciences, Autonomous University of Sinaloa, Ciudad Universitaria, Josefa Ortiz de Domínguez S/N y Avenida de las Américas, Culiacán, Sinaloa 80010, México

E-mail: rosaliorp@uas.edu.mx

Key words: leprosy, protein tyrosine phosphatase non-receptor type 22 gene, Mexican mestizo from regions with higher incidence of leprosy. Genotypic $(\mathrm{P}=0.44)$ and allelic frequencies $(\mathrm{P}=0.45)$ of the rs 2476601 polymorphism were similar between patients and controls; genotypic frequencies were 91 vs. $94 \%$ for CC and 9 vs. $6 \%$ for CT, and the TT genotype was absent in both groups. Allelic frequencies were 96 vs. $97 \%$ for $\mathrm{C}$, and 4 vs. $3 \%$ for $\mathrm{T}$. In the same way, the genotypic $(\mathrm{P}=0.46)$ and allelic frequencies $(\mathrm{P}=0.47)$ from MB patients and controls were similar. In conclusion, there was a lack of association of the PTPN22 rs2476601 polymorphism with the development of leprosy, which suggests that this SNP was not a genetic risk factor for leprosy in the Mexican mestizo population studied.

\section{Introduction}

Leprosy remains an important health issue worldwide, particularly in Asia, Africa and Latin America (1). The disease is caused by Mycobacterium leprae, an obligate intracellular acid-fast bacillus that causes a chronic granulomatous infection of the skin and peripheral nerves of susceptible individuals, triggering irreversible impairment of nerve function and consequent chronic disability (2). Based on clinical, histological, bacteriological and immunological characteristics, the Ridley-Jopling (3) classification defines leprosy as: i) Lepromatous leprosy (LL); ii) tuberculoid leprosy (TT), and three dimorphic (D) forms; iii) borderline tuberculoid (BT), iv) borderline borderline (BB); and v) borderline lepromatous (BL). In addition, the World Health Organization 
(WHO) defines BB, BL and LL patients as multibacillary (MB) and BT and TT patients as paucibacillary $(3,4)$.

Genetic factors, particularly host genes that modulate immune responses, have been suggested to favor the acquisition of leprosy and the clinical course of the disease $(5,6)$. Lymphoid protein tyrosine phosphatase (LYP) is an enzyme encoded by the protein tyrosine phosphatase non-receptor type 22 (PTPN22) gene located at chromosome 1p13.3-13.1. This protein belongs to the PEST group of nonreceptor classical class I PTPs (protein tyrosine phosphatase), characterized to be cysteine-based and restricted to hematopoietic cells, mainly lymphoid cells (7-9). Therefore, LYP is expressed in developing $\mathrm{T}$ cells and negatively regulates $\mathrm{T}$-cell signaling by acting together with the tyrosine-protein kinase Csk, a potent suppressor of T-cell activation, to inhibit this activation through the T-cell receptor (TCR) $(10,11)$. The transitional mutation rs2476601 in exon 14 of the PTPN22 gene changes a cytosine to a thymine at position $1858(1858 \mathrm{C}>\mathrm{T})$, resulting in a single amino acid change of an arginine to a tryptophan at codon 620 (R620W) (12). Consequently, the mutated 1858T allele encodes LYP-Trp620, a more efficient inhibitor of T cell activation than the normal LYP-Arg620. LYP-Trp620 is a gain-of-function variant involved in the earliest events of TCR signaling; for example, it decreases the leukocyte-specific protein tyrosine kinase-mediated phosphorylation of the TCRs chain (13).

Bottini et al (12) were the first to report an association between polymorphism rs2476601 of PTPN22 and type 1 diabetes mellitus in North American and Italian populations. Further studies have indicated that rs2476601 participates in the susceptibility to gram-positive infections (14), protection from tuberculosis $(15,16)$ and susceptibility to leprosy $(17,18)$.

Therefore, the aim of the present study was to analyze the association between polymorphism rs2476601 of PTPN22 gene with the susceptibility to developing leprosy in Mexican patients, using TaqMan Pre-Designed single nucleotide polymorphism (SNP) genotyping assays.

\section{Materials and methods}

Subjects. A total of 189 leprosy patients from the Mexican states with higher incidence of leprosy: Sinaloa, Guadalajara, Michoacán, Oaxaca, Guanajuato, Mexico City and Guerrero, were recruited from July 2011 to January 2016 and classified according to Ridley-Jopling and WHO criteria $(3,4)$. Of these, 165 cases were MB (141 LL and $24 \mathrm{D})$ and 24 cases were PB. Patients were $44 \%$ female and $56 \%$ male with a mean age of $52 \pm 18.8$ years old. A control group comprised of 231 healthy unrelated subjects matched by ethnicity (42\% female and $58 \%$ male, with a mean age of $78 \pm 12$ years). All study participants were classified as Mexican mestizos $(19,20)$. The investigation was performed according to the ethical guidelines of the 2008 Declaration of Helsinki. The Ethics and Research Committee of the Faculty of Biological and Chemical Sciences, Autonomous University of Sinaloa (Culiacán, Mexico), approved the study. Written informed consent was provided by all study participants prior to enrollment.

Genotyping. Total genomic DNA, from patients and healthy subjects, was extracted from samples of peripheral blood (5 ml) following Miller's salting-out method (21). Genotyping for rs2476601 (1858C>T, R620W) in the PTPN22 gene was performed using a Real Time Thermocycler (StepOnePlus; Applied Biosystems; Thermo Fisher Scientific, Inc., Waltham, MA, USA) and TaqMan Pre-Designed SNP genotyping assays method. C_16021387_20 was the SNP genotyping assay ID (Applied Biosystems; Thermo Fisher Scientific, Inc.). Genotyping assays were performed according to manufacturer's protocols. Optimization of the TaqMan SNP genotyping assay was performed using controls of known CC, CT and TT genotypes selected through DNA sequencing.

Statistical analysis. Demographic and clinical variables of leprosy patients and controls were presented as mean \pm standard deviation and frequencies. Hardy-Weinberg equilibrium and genotypic and allelic frequencies were assessed using the $\chi^{2}$ test. SNP associations were measured by odds ratio (OR) with $95 \%$ confidence interval $(\mathrm{CI}) . \mathrm{P}<0.05$ was considered to indicate a statistically significant difference. PASW v18.0 (SPSS, Inc., Chicago, IL, USA) software was used for analysis.

\section{Results}

Population characteristics. We investigated the possible association between polymorphism rs2476601 of PTPN22 and leprosy in 420 Mexican mestizo individuals (189 patients with leprosy and 231 healthy controls). The demographic and clinical data of the patients with leprosy are presented in Table I.

Genotypic and allelic frequencies of polymorphism rs 2476601 of PTPN22. The SNP rs2476601 was in Hardy-Weinberg equilibrium in patients and controls (data not shown; $\mathrm{P}>0.05$ ). The distributions of allelic and genotypic frequencies between both groups are displayed in Table II. Genotypic frequencies did not differ significantly $(\mathrm{P}=0.44)$ between patients and controls: The frequencies were 91 vs. $94 \%$ for CC; 9 vs. $6 \%$ for $\mathrm{CT}$; and the TT genotype was absent in both groups. Allelic frequencies in patients and controls were: 96 vs. $97 \%$ for C; and 4 vs. $3 \%$ for $\mathrm{T}(\mathrm{P}=0.45)$.

Additionally, the association with MB cases was examined as it is the most frequent clinical phenotype of leprosy in the Mexican population (22). Table III shows the genotypic and allelic frequencies $(\mathrm{P}=0.46$ and $\mathrm{P}=0.47$, respectively) between $\mathrm{MB}$ patients and controls. The frequencies were the same as those observed in leprosy generally (Table II).

Table IV presents the frequencies that correspond to the clinical subtypes of MB. Genotypic frequencies between the D forms of MB leprosy (BB and BL) and controls were 92 vs. $94 \%$ for $\mathrm{CC}$, and 8 vs. $6 \%$ for $\mathrm{CT}(\mathrm{P}=0.90)$; between $\mathrm{LL}$ patients and controls were 91 vs. $94 \%$ for CC, and 9 vs. $6 \%$ for CT $(\mathrm{P}=0.49)$; and between LL and D patients were $91 \mathrm{vs.} 92 \%$ for $\mathrm{CC}$, and 9 vs. $8 \%$ for $\mathrm{CT}(\mathrm{P}=1.00)$. As shown, TT genotype was absent in patients and controls. Allelic frequencies between $\mathrm{D}$ patients and controls were 94 vs. $98 \%$ for the $\mathrm{C}$ allele, and 6 vs. $2 \%$ for the $\mathrm{T}$ allele $(\mathrm{P}=0.49)$; between $\mathrm{LL}$ patients and controls were 96 vs. $98 \%$ for the C allele, and 4 vs. $2 \%$ for the $\mathrm{T}$ allele $(\mathrm{P}=0.68)$; and between $\mathrm{LL}$ and $\mathrm{D}$ patients were 96 vs. $94 \%$ for the $\mathrm{C}$ allele, and 4 vs. $6 \%$ for the $\mathrm{T}$ allele $(\mathrm{P}=0.76)$. Thus, overall, no association was observed between patients with MB leprosy and the polymorphism rs2476601 of PTPN22. 


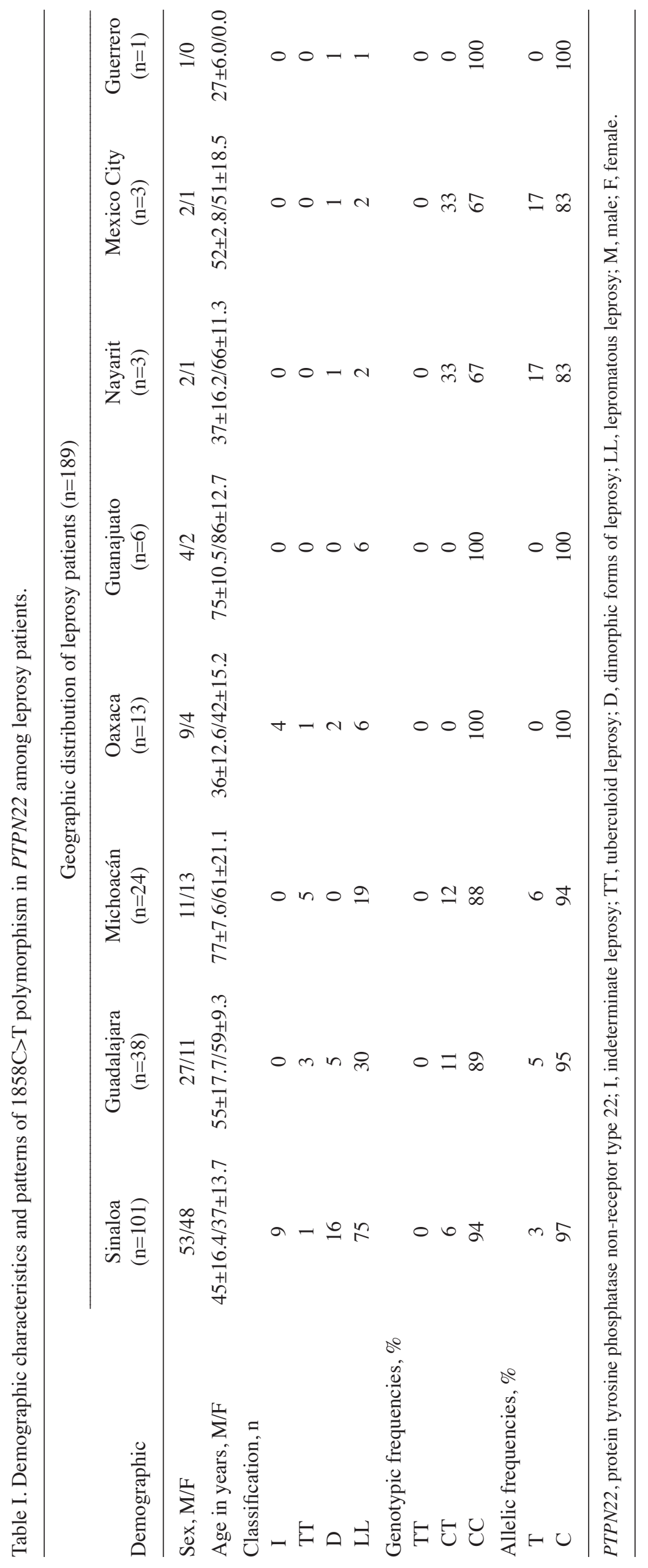


Table II. Allelic and gene frequencies of $1858 \mathrm{C}>\mathrm{T}$ polymorphism in PTPN22 in patients with leprosy and healthy controls.

\begin{tabular}{|c|c|c|c|c|}
\hline $1858 \mathrm{C}>\mathrm{T}$ & Leprosy, n (\%) & Controls, n (\%) & P-value & OR $(95 \%$ CI) \\
\hline Genotype & $\mathrm{n}=189$ & $\mathrm{n}=231$ & & \\
\hline $\mathrm{CC}$ & $173(91)$ & 217 (94) & - & - \\
\hline $\mathrm{CT}$ & $16(9)$ & $14(6)$ & 0.44 & $0.69(0.33-1.46)$ \\
\hline $\mathrm{TT}$ & $0(0)$ & $0(0)$ & - & - \\
\hline Allele & $\mathrm{n}=378$ & $n=462$ & & \\
\hline $\mathrm{C}$ & $362(96)$ & $448(97)$ & - & - \\
\hline $\mathrm{T}$ & $16(4)$ & $14(3)$ & 0.45 & $0.70(0.34-1.46)$ \\
\hline
\end{tabular}

The values are presented as frequency in percentage and number of the genotype or allele. The frequencies were compared between the groups by the $\chi^{2}$ test. Statistical significance was determined at $\mathrm{P}<0.05$. PTPN22, protein tyrosine phosphatase non-receptor type 22; OR, odds ratio; $\mathrm{CI}$, confidence interval.

Table III. Allelic and gene frequencies of $1858 \mathrm{C}>\mathrm{T}$ polymorphism in PTPN22 in patients with MB leprosy and healthy controls.

\begin{tabular}{|c|c|c|c|c|}
\hline $1858 \mathrm{C}>\mathrm{T}$ & MB patients, n (\%) & Controls, n (\%) & P-value & OR $(95 \% \mathrm{CI})$ \\
\hline Genotype & $n=165$ & $n=231$ & & \\
\hline $\mathrm{CC}$ & $151(91)$ & $217(94)$ & - & - \\
\hline $\mathrm{CT}$ & $14(9)$ & $14(6)$ & 0.46 & $0.69(0.32-1.50)$ \\
\hline TT & $0(0)$ & $0(0)$ & - & - \\
\hline Allele & $\mathrm{n}=330$ & $n=462$ & & \\
\hline $\mathrm{C}$ & $316(96)$ & $448(97)$ & - & - \\
\hline $\mathrm{T}$ & $14(4)$ & $14(3)$ & 0.47 & $0.70(0.33-1.50)$ \\
\hline
\end{tabular}

The values are presented as frequency in percentage and number of the genotype or allele. The frequencies were compared between the groups was analyzed by the $\chi^{2}$ test. Statistical significance was determined at $\mathrm{P}<0.05$. PTPN22, protein tyrosine phosphatase non-receptor type 22; OR, odds ratio; CI, confidence interval; MB multibacillary leprosy.

\section{Discussion}

Although leprosy is of infectious etiology, studies have demonstrated that a genetic component and its variability serve a crucial role in the establishment and progression of the disease $(5,6)$. In previous reports, our group observed that human leukocyte antigen (HLA)-DRB $1 * 01$ and HLA-A*28 alleles were associated with susceptibility to leprosy, whereas HLA-DRB $1 * 08$ was associated with resistance, in a Mexican mestizo population $(23,24)$. The rs 2476601 polymorphism of $P T P N 22$ has been associated with a negative regulatory function in T-cell signaling and with autoimmune diseases including type 1 diabetes (25), rheumatoid arthritis (26) and systemic lupus erythematosus (27), and several infectious diseases including tuberculosis and leprosy (15-18). Reduction of LYP activity by the $620 \mathrm{~W}$ variant may affect the development of regulatory $\mathrm{T}$ lymphocytes (Tregs), thus affecting the balance between effector $\mathrm{T}$ cells and Tregs (28). Accordingly, $\mathrm{T}$ cells appear anergic to $M$. leprae antigens in leprosy patients (18). Patients with LL have been found to exhibit an increase of CD25 $5^{\text {hi }}$ cells as compared to tuberculoid and healthy subjects, however there were also low levels of interferon (INF) $-\gamma$ and interleukin (IL)-17 in patients with CD25 ${ }^{\text {hi }}$ cells, therefore the
Tregs may have contributed to the decrease via regulation of lymphocytes T (29). By contrast, an increase in forkhead box P3 in circulating LL patients has been observed due to an increase of transforming growth factor- $\beta$ produced by T helper 3 cells (30). In this context, the current study analyzed the association between rs 2476601 polymorphism of PTPN22 with leprosy in a Mexican mestizo population. The distribution of the patients was in accordance with that reported by Larrea et al (22); among the states with the highest prevalence of leprosy were Sinaloa, Guadalajara and Michoacán, and there was a higher prevalence in men than in women, with an increased proportion of MB cases.

In agreement with one of seemingly only two other works studying this polymorphism in leprosy $(17,18)$, the current results indicates no association between genotypic and allelic frequencies of rs2476601 and susceptibility of developing leprosy. Rani et al (18) observed a significant difference in the frequency of the $1858 \mathrm{~T}$ allele between patients with lepromatous or tuberculoid leprosy and healthy controls in an Indian population, suggesting that this translocation contributes to T-cell signaling malfunction. By contrast, Aliparasti et al (17) observed no difference in the distribution of genotypic and allelic frequencies of this polymorphism between leprosy 
patients and healthy controls in an Iranian population. The presence or absence of the $1858 \mathrm{~T}$ allele may be associated with ethnicity, as previous studies have observed high frequency of this allele in Europeans (14) and low frequency in Asians (31). In agreement, Mexican mestizo patients exhibit a low frequency of the TT genotype of this allele (32). In general, these conflicting results suggest the existence of more than one mechanism leading to the observed T cell anergy in leprosy, independent or complementary to TCR regulation by LYP. In this sense, Sridevi et al (33) proposed a defective macrophage-T cell interaction as a mechanism leading to the low levels of the co-stimulatory molecules CD28, CD80 and CD86, as well as the low production of IL- 2 and INF- $\gamma$, observed in LL patients. More studies are required to further evaluate the association of polymorphisms of genes participating in immune-synapse interactions as potential risk factors for leprosy.

In conclusion, in the present study, the rs 2476601 polymorphism of PTPN22 did not appear be a genetic risk factor for leprosy in a Mexican mestizo population, perhaps due to the low frequency of the $\mathrm{T}$ allele and the absence of carriers of the TT genotype in both patients and controls. The present report is one of few studies that have evaluated the role of rs 2476601 in the development and clinical course of leprosy, and further study is required in populations with different ethnic background.

\section{Acknowledgements}

The authors are thankful to Dr Guzman Sanchez-Schmitz. (Boston Children's Hospital and Harvard Medical School, Boston, MA, USA) for critically reading and revising the manuscript on language, and Jesús Lázaro López-Vázquez (Instituto Nacional de Ciencias Médicas y Nutrición Salvador Zubirán, Mexico City, Mexico) for their role as a laboratory assistant.

\section{Funding}

This study was supported by the National Council of Science and Technology (CONACYT, grant no. 106152).

\section{Availability of data and materials}

The datasets used and/or analyzed during the current study are available from the corresponding author.

\section{Authors' contributions}

RAG, MFM and MGL diagnosed and treated the patients. MET, TGPS and NMTC conducted laboratory test. RRG, MTH and SEP collected the data and analyzed the results. RRP, IEG and JG wrote the manuscript. All authors read and approved the final manuscript.

\section{Ethics approval and consent to participate}

The Ethics and Research Committee of the Faculty of Biological and Chemical Sciences, Autonomous University of Sinaloa, approved the study. Written informed consent was provided by all study participants prior to enrollment. 


\section{Patient consent for publication}

Not applicable.

\section{Competing interests}

The authors declare no competing interests related to this manuscript.

\section{References}

1. World Health Organization (WHO): Leprosy. WHO, Geneva, 2018. https://www.who.int/en/news-room/fact-sheets/detail/ leprosy. Accessed February 9, 2018.

2. Britton WJ and Lockwood DN: Leprosy. Lancet 363: 1209-1219, 2004.

3. Ridley DS and Jopling WH: Classification of leprosy according to immunity. A five-group system. Int J Lepr Other Mycobact Dis 34: 255-273, 1966.

4. Mira MT: Genetic host resistance and susceptibility to leprosy. Microbes Infect 8: 1124-1131, 2006.

5. Alter A, Grant A, Abel L, Alcais A and Schurr E: Leprosy as a genetic disease. Mamm Genome 22: 19-31, 2011.

6. Zhang FR, Huang W, Chen SM, Sun LD, Liu H, Li Y, Cui Y, Yan XX, Yang HT, Yang RD, et al: Genomewide association study of leprosy. N Engl J Med 361: 2609-2618, 2009.

7. Alonso A, Sasin J, Bottini N, Friedberg I, Friedberg I, Osterman A, Godzik A, Hunter T, Dixon J and Mustelin T: Protein tyrosine phosphatases in the human genome. Cell 117: 699-711, 2004.

8. Andersen JN, Jansen PG, Echwald SM, Mortensen OH, Fukada T, Del Vecchio R, Tonks NK and Møller NP: A genomic perspective on protein tyrosine phosphatases: Gene structure, pseudogenes, and genetic disease linkage. FASEB J 18: 8-30, 2004.

9. Davidson D, Cloutier JF, Gregorieff A and Veillette A: Inhibitory tyrosine protein kinase p50csk is associated with protein-tyrosine phosphatase PTP-PEST in hemopoietic and non-hemopoietic cells. J Biol Chem 272: 23455-23462, 1997.

10. Cloutier JF and Veillette A: Cooperative inhibition of T-cell antigen receptor signaling by a complex between a kinase and a phosphatase. J Exp Med 189: 111-121, 1999.

11. Davidson D and Veillette A: PTP-PEST, a scaffold protein tyrosine phosphatase, negatively regulates lymphocyte activation by targeting a unique set of substrates. EMBO J 20: 3414-3426, 2001.

12. Bottini N, Musumeci L, Alonso A, Rahmouni S, Nika K Rostamkhani M, MacMurray J, Meloni GF, Lucarelli P, Pellecchia M, et al: A functional variant of lymphoid tyrosine phosphatase is associated with type I diabetes. Nat Genet 36: 337-338, 2004.

13. Vang T, Congia M, Macis MD, Musumeci L, Orrú V, Zavattari P, Nika K, Tautz L, Taskén K, Cucca F, et al: Autoimmune-associated lymphoid tyrosine phosphatase is a gain-of-function variant. Nat Genet 37: 1317-1319, 2005.

14. Chapman SJ, Khor CC, Vannberg FO, Maskell NA, Davies CW, Hedley EL, Segal S, Moore CE, Knox K, Day NP, et al: PTPN22 and invasive bacterial disease. Nat Genet 38: 499-500, 2006.

15. Lamsyah H, Rueda B, Baassi L, Elaouad R, Bottini N, Sadki K and Martin J: Association of PTPN22 gene functional variants with development of pulmonary tuberculosis in Moroccan population. Tissue Antigens 74: 228-232, 2009.

16. Lopez-Escamez JA: A variant of PTPN22 gene conferring risk to autoimmune diseases may protect against tuberculosis. J Postgrad Med 56: 242-243, 2010.

17. Aliparasti MR, Almasi S, Majidi J, Zamani F, Khoramifar AR and Azari ARF: Protein tyrosine phosphatase non-receptor type 22 gene polymorphism C1858T is not associated with leprosy in Azerbaijan, Northwest Iran. Indian J Hum Genet 19: 403-407, 2013.

18. Rani R, Singh A, Israni N, Singh A, Sharma P and Kar HK: The role of polymorphic protein tyrosine phosphatase non-receptor type 22 in leprosy. J Invest Dermatol 129: 2726-2728, 2009.
19. Rangel-Villalobos H, Muñoz-Valle JF, González-Martín A, Gorostiza A, Magaña MT and Páez-Riberos LA: Genetic admixture, relatedness, and structure patterns among Mexican populations revealed by the Y-chromosome. Am J Phys Anthropol 135: 448-461, 2008.

20. Rubi-Castellanos R, Anaya-Palafox M, Mena-Rojas E, Bautista-España D, Muñoz-Valle JF and Rangel-Villalobos H: Genetic data of 15 autosomal STRs (Identifiler kit) of three Mexican Mestizo population samples from the States of Jalisco (West), Puebla (Center), and Yucatan (Southeast). Forensic Sci Int Genet 3: e71-e76, 2009.

21. Miller SA, Dykes DD and Polesky HF: A simple salting out procedure for extracting DNA from human nucleated cells. Nucleic Acids Res 16: 1215, 1988.

22. Larrea MR, Carreño MC and Fine PE: Patterns and trends of leprosy in Mexico: 1989-2009. Lepr Rev 83: 184-194, 2012.

23. Aguilar-Medina M, Escamilla-Tilch M, Frías-Castro LO, Romero-Quintana G,Estrada-García I,Estrada-Parra S, Granados J, Arambula Meraz E, Sánchez-Schmitz G, Khader SA, et al: HLA Alleles are genetic markers for susceptibility and resistance towards leprosy in a Mexican Mestizo population. Ann Hum Genet 81: 35-40, 2017.

24. Escamilla-Tilch M, Torres-Carrillo NM, Payan RR, Aguilar-Medina M, Salazar MI, Fafutis-Morris M, Arenas-Guzman R, Estrada-Parra S, Estrada-Garcia I and Granados J: Association of genetic polymorphism of HLA-DRB1 antigens with the susceptibility to lepromatous leprosy. Biomed Rep 1: 945-949, 2013.

25. Abdelrahman HM, Sherief LM, Abd Elrahman DM, Alghobashy A, Elsaadani HF and Mohamed RH: The association of PTPN22 (rs2476601) and IL2RA (rs11594656) polymorphisms with T1D in Egyptian children. Hum Immunol 77: 682-686, 2016.

26. Song GG, Bae SC, Kim JH and Lee YH: The PTPN22 C1858T polymorphism and rheumatoid arthritis: A meta-analysis. Rheumatol Int 33: 1991-1999, 2013.

27. Zheng J, Ibrahim S, Petersen F and Yu X: Meta-analysis reveals an association of PTPN22 C1858T with autoimmune diseases, which depends on the localization of the affected tissue. Genes Immun 13: 641-652, 2012.

28. Maine CJ, Hamilton-Williams EE, Cheung J, Stanford SM, Bottini N, Wicker LS and Sherman LA: PTPN22 alters the development of regulatory T cells in the thymus. J Immunol 188: 5267-5275, 2012

29. Saini $C$, Ramesh $V$ and Nath I: Increase in TGF- $\beta$ secreting CD4(+)CD25(+) FOXP3(+) T regulatory cells in anergic lepromatous leprosy patients. PLoS Negl Trop Dis 8: e2639, 2014.

30. Kumar S, Naqvi RA, Ali R, Rani R, Khanna N and Rao DN: FoxP3 provides competitive fitness to CD4(+)CD25(+) T cells in leprosy patients via transcriptional regulation. Eur J Immunol 44: 431-439, 2014.

31. Kawasaki E, Awata T, Ikegami H, Kobayashi T, Maruyama T, Nakanishi K, Shimada A, Uga M, Kurihara S, Kawabata Y, et al: Systematic search for single nucleotide polymorphisms in a lymphoid tyrosine phosphatase gene (PTPN22): association between a promoter polymorphism and type 1 diabetes in Asian populations. Am J Med Genet A 140: 586-593, 2006.

32. Torres-Carrillo NM, Ruiz-Noa Y, Martínez-Bonilla GE, Leyva-Torres SD, Torres-Carrillo N, Palafox-Sánchez CA, Navarro-Hernández RE, Rangel-Villalobos H, Oregón-Romero E and Muñoz-Valle JF: The +1858C/T PTPN22 gene polymorphism confers genetic susceptibility to rheumatoid arthritis in Mexican population from the Western Mexico. Immunol Lett 147: 41-46, 2012.

33. Sridevi K, Neena K, Chitralekha KT, Arif AK, Tomar D and Rao DN: Expression of costimulatory molecules (CD80, CD86, CD28, CD152), accessory molecules (TCR alphabeta, TCR gammadelta) and $\mathrm{T}$ cell lineage molecules (CD4+, CD8+) in PBMC of leprosy patients using Mycobacterium leprae antigen (MLCWA) with murabutide and T cell peptide of Trat protein. Int Immunopharmacol 4: 1-14, 2004. 